\title{
ANALISIS KUALITAS PELAYANAN FASILITAS TERMINAL KAMPUNG RAMBUTAN BERDASARKAN TINGKAT KEPUASAN PENGGUNA
}

\author{
(Analysis of Quality Service of Kampung Rambutan Bus Station Based on User Satisfaction) \\ Rizka Kurniawati ${ }^{1}$, Nuryani Tinumbia ${ }^{1}$ \\ 1Program Studi Teknik Sipil, Fakultas Teknik, Universitas Pancasila, Jakarta, Indonesia \\ E-mail: rizkakur31@gmail.com
}

\begin{abstract}
ABSTRAK
Keberadaan terminal dalam jaringan transportasi sangat penting, sebab merupakan tempat perpindahan moda. Terminal bus Kampung Rambutan merupakan terminal Tipe-A yang melayani hilir mudik penumpang dari dan ke berbagai kota di provinsi lain maupun berbagai tempat di dalam DKI Jakarta. Sehingga kinerja terminal adalah hal yang sangat penting agar dapat menunjang kelancaran, keamanan dan kenyamanan penumpang dalam berpindah moda. Penelitian ini bertujuan untuk mengetahui kualitas pelayanan terminal Kampung Rambutan terhadap kepuasan pengguna, sehingga diharapkan dapat memberi rekomendasi perbaikan pelayanan fasilitas Terminal Kampung Rambutan. Survey dilakukan dengan penyebaran kuisioner kepada pengguna terminal (penumpang) dan inventarisasi kondisi eksisting terminal. Analisis dilakukan dengan menggunakan Importance-Performance Analysis (IPA) dan statistik deskriptif. Hasil analisis menunjukkan bahwa terdapat beberapa indikator menjadi prioritas utama yang harus diperbaiki menurut pengguna terminal yaitu fasilitas bagi pengguna berkebutuhan khusus (difabel), penyampaian informasi gangguan perjalanan kendaraan bus, penyediaan informasi keberangkatan dan kedatangan bus, lokasi informasi yang strategis, serta keamanan dan kenyamanan.
\end{abstract}

Kata Kunci: Kualitas Pelayanan, Terminal Bus, Importance-Performance Analysis

\begin{abstract}
The existence of a bus station in the transportation network is very important, because it is a place of modal transfer. Kampung Rambutan bus station is a Type-A bus station that serves transportation of intercity interprovincial (AKAP) and intercity within DKI Jakarta (AKDP). Thus the performance of the terminal is very important in order to support the smooth running, safety and comfort of passengers in modal transfer. This study aims to determine the service quality of Kampung Rambutan bus station to user satisfaction, and provide recommendations for improving the facilities of Kampung Rambutan bus station. The survey was conducted by distributing questionnaires to the users (passengers). Analysis using Importance-Performance Analysis (IPA) and descriptive statistics. The analysis shows that there are several indicators become the main priority for improvement according to the users, namely facilities for disability users, notification of bus trip disruption information, information of departure and arrival, strategic location of information, safety and comfort.
\end{abstract}

Keywords: Service Quality, Bus Station, Importance-Performance Analysis 


\section{PENDAHULUAN}

Terminal Kampung Rambutan berlokasi di Kecamatan Ciracas, Jakarta Timur, yang mengakses Jalan Lingkar Luar Selatan. Luas terminal ini adalah $141.000 \mathrm{~m}^{2}$, yang terbagi menjadi dua bagian, yaitu terminal dalam kota seluas $87.200 \mathrm{~m}^{2}$ dan terminal antar kota seluas 53.800 $\mathrm{m}^{2}$. Terminal ini merupakan terminal tipe A yang melayani penumpang Angkutan Antar Kota Antar Propinsi (AKAP) Jawa Tengah, Jawa Tmur, Jawa Barat, dan Banten, dan Antar Kota Dalam Provinsi (AKDP) berbagai jurusan dalam kota, Terminal ini juga terdapat Halte Transjakarta Koridor 7 yang dilewati Kampung Rambutan-Kampung Melayu dan Angkutan Perbatasan Terintegrasi Busway (APTB) jurusan Kampung Rambutan-Bekasi via Tol Cikunir.

Keberadaan Terminal Kampung Rambutan menjadi signifikan sebagai salah satu simpul jaringan transportasi di DKI Jakarta, sehingga kinerja dan kualitas pelayanan terminal adalah hal yang sangat penting agar dapat menunjang kelancaran, keamanan dan kenyamanan penumpang dalam berpindah moda. Sehingga perlu adanya evaluasi kualitas pelayanan eksisting terminal ini. Tujuan dari penelitian ini adalah untuk mengetahui kualitas pelayanan terminal Kampung Rambutan terhadap tingkat kepuasan pengguna.

Menurut Undang-Undang Republik Indonesia Nomor 14 Tahun 1992 Pasal 9 dan 10, bahwa terminal merupakan sebagai penunjang untuk kelancaran mobilitas orang maupun arus barang dan untuk terlaksananya keterpaduan intra dan antar moda secara lancar dan tertib, di tempat-tempat tertentu dapat dibangun dan diselenggarakan terminal. Wright, dkk. (1997) menjelaskan fungsi terminal, yaitu sebagai titik konsentrasi (traffic consentration) dimana penumpang berkumpul dari segala arah untuk melanjutkan perjalanan ke tempat tujuan, sebagai titik disperse (classification and sorting) dimana penumpang menyebar sesuai dengan tujuannya, sebagai titik tempat berganti moda angkutan (traffic interchange) dimana terjadi perpindahan moda angkutan yang dilakukan oleh penumpang untuk melanjutkan perjalanan, dan sebagai titik pusat layanan (service avaibility) untuk bongkar muat (loading and unloading), penyimpanan jangka pendek (storage) dan tempat proses untuk pembelian tiket, menunggu, menyimpan bawaan penumpang dan prosedur lain.

Jenis terminal berdasarkan jenis angkutannya dapat dikelompokkan menjadi dua, yaitu terminal angkutan penumpang dan terminal angkutan barang. Berdasarkan Keputusan Menteri Perhubungan Nomor 31 Tahun 1995 (KM No. 30/95), terminal angkutan penumpang dibagi atas tipe $A$, tipe $B$, dan tipe $C$, terminal barang dikelompokkan menjadi terminal barang khusus dan terminal barang umum.

Peraturan Menteri Perhubungan Nomor 132 Tahun 2015 tentang Penyelenggaraan Terminal Penumpang Angkutan Jalan mengatur fasilitas terminal penumpang yang terdiri dari fasilitas utama dan penunjang.

1. Fasilitas utama terminal yang terdiri dari: (1) Jalur keberangkatan kendaraan; (2) Jalur kedatangan kendaraan; (3) Ruang tunggu penumpang, pengantar, dan/atau penjemput; (4) Tempat parkir kendaraan; (5) Fasilitas pengelolaan lingkungan hidup (waste management); (6) Perlengkapan jalan; (7) Fasilitas penggunaan teknologi; (8) Media informasi;

Penanganan pengemudi; (10) Pelayanan pengguna terminal dari perusahaan bus (customer service); (11) Fasilitas pengawasan keselamatan; (12) Jalur kedatangan penumpang; (13) Ruang tunggu keberangkatan (boarding); (14) Ruang pembelian tiket; (15)Ruang pembelian tiket untuk bersama; (16) Outlet pembelian tiket secara online (single outlet ticketing online); (17) Pusat informasi (information center); (18) Papan perambuan dalam terminal (Signage); (19) Papan pengumuman; (20) Layanan bagasi (Lost and found); (21) Ruang penitipan barang (lockers); (22). Tempat berkumpul darurat (assembly point); (23) Jalur evakuasi bencana dalam terminal.

2. Fasilitas penunjang sebagai fasilitas pelengkap dalam pengoperasian terminal antara lain: (1) Fasilitas penyandang cacat dan ibu hamil atau menyusui; (2) Fasilitas keamanan (checking point/metal detector/CCTV); (3) Fasilitas pelayanan keamanan; (4) Fasilitas istirahat awak kendaraan; (5) Fasilitas ramp check; (6) Fasilitas pengendapan kendaraan; (7) Fasilitas bengkel yang diperuntukkan bagi operasional bus; (8) Fasilitas kesehatan; (9) Fasilitas peribadatan; (10)Tempat transit penumpang (hall); (11) Alat pemadam kebakaran; (12) Fasilitas umum, yang meliputi: Toilet; Fasilitas park and ride; Tempat istirahat awak kendaraan; Fasilitas pereduksi pencemaran udara dan kebisingan; Fasilitas pemantau kualitas udara dan gas buang; Fasilitas kebersihan, perawatan terminal, dan janitor; Fasilitas perbaikan ringan kendaraan umum; Fasilitas perdagangan, pertokoan, kantin pengemudi; Area merokok; Fasilitas restoran; Fasilitas ATM; Fasilitas pengantar barang (trolley dan tenaga angkut); Fasilitas telekomunikasi dan area dengan jaringan internet; Fasilitas penginapan; Fasilitas keamanan; Ruang anak-anak; Media pengaduan layanan; Fasilitas umum lainnya sesuai kebutuhan.

Standar pelayanan terminal penumpang berdasarkan Peraturan Menteri Perhubungan Republik Indonesia Nomor PM 40 Tahun 2015, disediakan dan dilaksanakan oleh penyelenggara terminal penumpang angkutan jalan yang mencakup 6 (enam) pelayanan, antara lain:

1. Pelayanan keselamatan;

2. Pelayanan keamanan;

3. Pelayanan kehandalan/keteraturan;

4. Pelayanan kenyamanan;

5. Pelayanan kemudahan/keterjangkauan;

6. Pelayanan kesetaraan

\section{Kualitas Pelayanan}

Parasuraman dkk. (1990), menyatakan bahwa atribut yang dapat digunakan untuk mengevaluasi kualitas pelayanan dilihat dari lima dimensi pokok:

1. Bukti fisik (tangible), yaitu kemampuan suatu pengelola dalam menunjukan eksistensinya kepada pihak eksternal. 
2. Keandalan (reliability), yaitu kemampuan pengelola untuk memberikan pelayanan sesuai dengan yang dijanjikan serta akurat dan terpercaya.

3. Daya tanggap (responsiveness), yaitu suatu kebijakan untuk membantu dan memberikan pelayanan yang cepat (responsive) dan tepat kepada pelanggan dengan penyampaian informasi yang jelas.

4. Jaminan dan kepastian (assurance), yaitu pengetahuan,kesopanan dan kemampuan para pegawai Terminal Kampung Rambutan untuk menumbuhkan rasa percaya para pelanggan.

5. Empati (empathy), yaitu memberikan perhatian yang tulus dan bersifat individual atau pribadi yang diberikan kepada para pelanggan dengan berupaya memahami keinginan konsumen.

Konsumen akan menggunakan dimensi kualitas untuk membentuk penilaian terhadap kualitas jasa yang merupakan dasar untuk membandingkan harapan dan kinerja terhadap jasa (Wibowo, 2013).

\section{Kepuasan Pelanggan}

Menurut Swastha (2000), kepuasan pelanggan adalah suatu dorongan keinginan individu yang diarahkan pada tujuan untuk memperoleh kepuasan. Sedangkan Rangkuti (2003), menyatakan kepuasan pelanggan merupakan respon pelanggan terhadap kesesuaian antara tingkat kepentingan sebelumnya dan kinerja aktual yang dirasakan setelah pemakaian. Kepuasan pelanggan ditentukan oleh berbagai jenis pelayanan yang didapatkan oleh pelanggan selama menggunakan beberapa tahapan pelayanan tersebut. Ketidakpuasan yang diperoleh pada tahap awal pelayanan menimbulkan persepsi berupa mutu pelayanan untuk tahapan selajutnya. Irawan (2003), mengemukakan bahwa terdapat lima komponen yang dapat mendorong kepuasan pelanggan yaitu kualitas produk, kualitas pelayanan, faktor emosional, harga, dan kemudahan.

\section{Importance-Performance Analysis}

Importance-Performance Analysis (IPA) merupakan alat bantu dalam menganalisis atau yang digunakan untuk membandingkan sampai sejauh mana antara kinerja yang dapat dirasakan oleh pengguna jasa dibandingkan terhadap tingkat kepuasan yang diinginkan. Dalam mengukur tingkat kepentingan dan tingkat kepuasan terhadap jawaban responden digunakan skala 5 tingkat (skala Likert). Tingkat kesesuaian merupakan hasil perbandingan antara skor kinerja pelaksanaan dengan skor kepentingan, sehingga tingkat kesesuaian akan menentukan skala prioritas yang akan dipakai dalam penanganan faktor yang mempengaruhi kepuasan pengguna.

Tingkat kinerja penyedia pelayanan dinyatakan dengan $X$ dan tingkat kepentingan pengguna pelayanan dengan $Y$ sebagai berikut:

$\mathrm{TK}_{\mathrm{i}}=\frac{\mathrm{Xi}}{\mathrm{Y} 1} \times 100 \%$

$\bar{x}=\frac{2 \mathrm{x}}{\mathrm{N}}$

$\overline{\mathrm{Y}}=\frac{\mathrm{ZY}}{\mathrm{N}}$

Keterangan:

$\mathrm{Tk}_{\mathrm{i}}=$ Tingkat kesesuaian responden

$\mathrm{Xi}=$ Skor penilaian pelaksanaan kinerja pelayanan

$Y i=$ Skor penilaian kepentingan pengguna

$\overline{\mathrm{X}}=$ Skor rata-rata tingkat kepuasan/kinerja

$\bar{Y}=$ Skor rata-rata tingkat kepentingan

$\mathrm{N}=$ Jumlah responden

Selanjutnya dilakukan pemetaan dari atribut dengan dijabarkan atau dikelompokkan dalam satu dari empat kuadran yang disebut diagram kartesius yang dibatasi oleh sumbu $X$ mewakili kinerja dan sumbu $Y$ mewakili harapan seperti terlihat dari diagram dibawah ini:

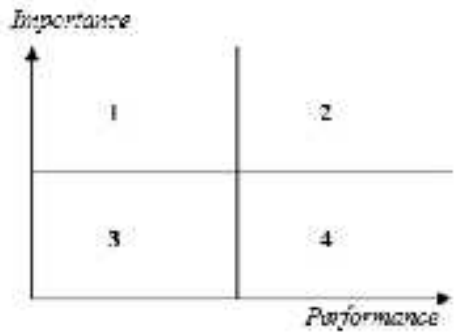

Gambar 1. Diagram Kartesius untuk ImportancePerformance Analysis

Penjelasan keempat kuadran diagram kartesius di atas adalah sebagai berikut (Idris, 2009):

1. Kuadran 1 yaitu importance tinggi sedangkan performance rendah, artinya pada kondisi ini dari sisi kepentingan pengguna jasa, di mana faktor yang mempengaruhi pelayanan pada tingkat tinggi. Sedangkan dari sisi kepuasan, konsumen merasakan tingkat yang rendah (tidak puas) sehingga menuntut adanya perbaikan atribut oleh pengusaha.

2. Kuadran 2 yaitu importance tinggi sedangkan performance juga tinggi, artinya pada kondisi ini dari sisi pengguna jasa, di mana faktor yang mempengaruhi pelayanan pada tingkat yang tinggi. Sedangkan kepuasan pengguna jasa juga pada tingkat yang tinggi (sudah puas). Dalam hal ini pengusaha diharapkan dapat mempertahankan pelayanan atau kinerjanya.

3. Kuadran 3 yaitu importance rendah sedangkan performance juga rendah, artinya pada kondisi ini faktor yang berhubungan dengan pelayanan tidak penting bagi pengguna, kinerja pengusaha biasabiasa saja dan juga pengguna tidak merasa puas dengan pelayanan yang diberikan.

4. Kuadran 4 yaitu importance rendah sedangkan performance tinggi, artinya pada kondisi ini faktor yang mempengaruhi pelayanan tidak penting bagi pengguna tetapi pengguna sudah merasa puas.

\section{METODE}

Penelitian berlokasi di Terminal Kampung Rambutan, Jenis data yang digunakan adalah data primer dan sekunder. Survey dilakukan dengan penyebaran kuesioner kepada 99 responden yang dalam hal ini pengguna terminal (penumpang bus) untuk menangkap kepuasan dan haraparan pengguna terhadap fasilitas terminal eksisting. Untuk data sekunder meliputi data jumlah pengguna Terminal Kampung Rambutan yang digunakan untuk menghitung jumlah minimal responden dengan menggunakan persamaan Slovin (Sugiyono, 2013). 
Terdapat 5 indikator yang dinilai responden perihal kepuasan pengguna terhadap pelayanan terminal yakni: bukti fisik (tangible), keandalan (reliability), daya tanggap (responsiveness); jaminan (assurance); empati (emphaty), dengan 5 skala penilaian (skala Likert) yaitu 1 sangat tidak baik - 5 sangat baik untuk penilaian kinerja terminal dan 1 sangat tidak penting -5 sangat penting untuk penilaian harapan

Tabel 1. Variabel Pelayanan berdasarkan Pengguna Terminal Kampung Rambutan

\begin{tabular}{|c|c|}
\hline & Indikator \\
\hline \multicolumn{2}{|c|}{ Bukti fisik (tangible) } \\
\hline 1 & Adanya lajur pejalan kaki yang aman \\
\hline 2 & $\begin{array}{l}\text { Fasilitas keselamatan yang memadai (jalur evakuasi dan alat } \\
\text { pemadam keakaran) }\end{array}$ \\
\hline 3 & Pos, fasilitas dan petugas kesehatan yang cukup \\
\hline 4 & $\begin{array}{l}\text { Pos keamanan, kamera pengawas/CCTV dan titik } \\
\text { pengamanan yang cukup }\end{array}$ \\
\hline 5 & Adanya petugas keamanan di terminal \\
\hline 6 & Tempat duduk dengan kapasitas memadai di ruang tunggu \\
\hline 7 & Toilet dengan jumlah yang cukup \\
\hline 8 & Fasilitas ibadah dengan luasan yang cukup \\
\hline 9 & Adanya petugas kebersihan \\
\hline 10 & $\begin{array}{l}\text { Kawasan merokok, ruang baca dan hotspot area yang } \\
\text { cukup }\end{array}$ \\
\hline 11 & Lampu penerangan di ruangan yang cukup \\
\hline 12 & $\begin{array}{l}\text { Tempat penitipan barang dan fasilitas pengisian baterai } \\
\text { yang cukup }\end{array}$ \\
\hline 13 & Tempat parkir kendaraan umum dan pribadi yang cukup \\
\hline 14 & Tersedianya fasilitas untuk pengguna disabilitas \\
\hline 15 & Ruang menyusui yang memadai dan bersih \\
\hline \multicolumn{2}{|c|}{ Keandalan (reliability) } \\
\hline 16 & Jadwal keberangkatan dan kedatangan kendaraan tepat \\
\hline 17 & Loket penjuakan tiket tetap dan teratur \\
\hline 18 & $\begin{array}{l}\text { Letak jalur keberangkatan dan kedatangan kendaraan tetap } \\
\text { dan teratur }\end{array}$ \\
\hline \multicolumn{2}{|r|}{ Daya tanggap (responsiveness) } \\
\hline 19 & $\begin{array}{l}\text { Informasi fasilitas keselamatan dan kesehatan tersedia } \\
\text { dengan jelas }\end{array}$ \\
\hline 20 & $\begin{array}{l}\text { Penyampaian informasi gangguan perjalanan bus dengan } \\
\text { jelas }\end{array}$ \\
\hline 21 & $\begin{array}{l}\text { Informasi keberangkatan dan kedatangan bus selalu } \\
\text { tersedia }\end{array}$ \\
\hline 22 & $\begin{array}{l}\text { Informasi pelayanan terletak di tempat strategis, mudah } \\
\text { didengar dan jelas terbaca }\end{array}$ \\
\hline \multicolumn{2}{|c|}{ Jaminan (assurance) } \\
\hline 23 & Pengguna terminal mendapatkan jaminan keselamatan \\
\hline 24 & Pengguna merasa aman dan nyaman di terminal \\
\hline 25 & Adanya media pengaduan gangguan keamanan \\
\hline \multicolumn{2}{|r|}{ Empati (emphaty) } \\
\hline 26 & Seluruh petugas di terminal selalu tersedia dalam melayani \\
\hline
\end{tabular}

Tingkat kepuasan pengguna dianalisis dengan metode IPA, dan untuk karakteristik responden dianalisis dengan statistik deskriptif.

\section{HASIL DAN PEMBAHASAN}

\section{Pengujian Statistik}

Pengujian statistik terdiri dari uji validitas dan uji reliabilitas. Teknik yang dipakai untuk pengujian validitas kuesioner adalah dengan korelasi Product Moment Pearson. Uji validitas dengan nilai korelasi yang dihitung dinyatakan valid apabila nilai $r>0,361$ (nilai $r$ tabel dengan 30 responden dan nilai $\alpha=5 \%$ ). Berdasarkan hasil pengolahan data, didapatkan bahwa kuesioner bersifat valid. Sedangkan uji reliabilitas dengan teknik Alpha Cronbach. Berdasarkan hasil pengolahan data menunjukkan bahwa nilai pada kenyataan adalah 0,954 dan nilai pada harapan adalah 0,952 yang artinya nilai tersebut di atas nilai Alpha Cronbach yaitu 0,60.

\section{Karakteristik Responden}

Karakteristik responden didapatkan dari hasil kuesioner yang dibagikan ke penumpang Terminal Kampung Rambutan yang terbagi berdasarkan usia, jenis kelamin, pendidikan terakhir, jenis pekerjaan dan pendapatan per bulan.

Tabel 2. Karakteristik responden

\begin{tabular}{lc} 
Karakteristik Responden & $\%$ \\
\hline 1. Gender & $70 \%$ \\
\hline Pria & $30 \%$ \\
\hline Wanita & $22 \%$ \\
\hline 2. Usia & $42 \%$ \\
\hline 15-24 tahun & $27 \%$ \\
\hline 25-34 tahun & $9 \%$ \\
\hline 35-44 tahun & $6 \%$ \\
\hline 3. Pendidikan Terakhir & $51 \%$ \\
\hline SD/SMP & $20 \%$ \\
\hline SMA & $23 \%$ \\
\hline Diploma & $17 \%$ \\
\hline D4/S1 & $39 \%$ \\
\hline 4. Pekerjaan & $28 \%$ \\
\hline Pelajar/mahasiswa & $16 \%$ \\
\hline Pegawai & $18 \%$ \\
\hline Wiraswasta & $18 \%$ \\
\hline lain-lain & $37 \%$ \\
\hline Pendapatan (per bulan) \\
\hline Rp.1.000.000-Rp.3.000.000
\end{tabular}

\section{Metode Importance-Performance Analysis 1. Analisis Tingkat Kesesuaian}

Setiap skor kepentingan (Xi) dan skor harapan (Yi) merupakan penjumlahan dari masing-masing perkalian skor dengan bobot skala pengukuran. Tingkat kesesuaian merupakan hasil perbandingan skor kepuasan dengan skor kepentingan. Analisis tingkat kesesuaian menggunakan persamaan 1 , sehingga didapatkan nilai tingkat kesesuaian sebesar $69 \%$. Hasil perhitungan ditampilkan pada Tabel 3. Selanjutnya, nilai rata-rata indikator $X$ dan $\bar{Y}$ dihitung denḡan menggunakan persamaan (2) dan (3).

Tabel 3. Analisis tingkat kesesuaian dan kesenjangan

\begin{tabular}{ccccccc}
\hline $\begin{array}{c}\text { Nomor } \\
\text { Indikator }\end{array}$ & $X i$ & $Y i$ & $T k i$ & $X$ & $Y$ & Gap \\
\hline 1 & 309 & 430 & $72 \%$ & 3.12 & 4.34 & 1.22 \\
\hline 2 & 313 & 436 & $72 \%$ & 3.16 & 4.40 & 1.24 \\
\hline 3 & 302 & 420 & $72 \%$ & 3.05 & 4.24 & 1.19 \\
\hline 4 & 280 & 433 & $65 \%$ & 2.83 & 4.37 & 1.55 \\
\hline 5 & 332 & 443 & $75 \%$ & 3.35 & 4.47 & 1.12 \\
\hline 6 & 327 & 431 & $76 \%$ & 3.30 & 4.35 & 1.05 \\
\hline 7 & 304 & 423 & $72 \%$ & 3.07 & 4.27 & 1.20 \\
\hline 8 & 310 & 428 & $72 \%$ & 3.13 & 4.32 & 1.19 \\
\hline 9 & 308 & 430 & $72 \%$ & 3.11 & 4.34 & 1.23 \\
\hline 10 & 251 & 429 & $59 \%$ & 2.54 & 4.33 & 1.80 \\
\hline 11 & 307 & 438 & $70 \%$ & 3.10 & 4.42 & 1.32 \\
\hline 12 & 284 & 434 & $65 \%$ & 2.87 & 4.38 & 1.52 \\
\hline 13 & 337 & 444 & $76 \%$ & 3.40 & 4.48 & 1.08 \\
\hline 14 & 295 & 451 & $65 \%$ & 2.98 & 4.56 & 1.58 \\
\hline 15 & 297 & 437 & $68 \%$ & 3.00 & 4.41 & 1.41 \\
\hline 16 & 314 & 449 & $70 \%$ & 3.17 & 4.54 & 1.36 \\
\hline 17 & 315 & 445 & $71 \%$ & 3.18 & 4.49 & 1.31 \\
\hline 18 & 314 & 456 & $69 \%$ & 3.17 & 4.61 & 1.43 \\
\hline 19 & 296 & 433 & $68 \%$ & 2.99 & 4.37 & 1.38 \\
\hline 20 & 298 & 442 & $67 \%$ & 3.01 & 4.46 & 1.45 \\
\hline 21 & 301 & 450 & $67 \%$ & 3.04 & 4.55 & 1.51 \\
\hline 22 & 299 & 442 & $68 \%$ & 3.02 & 4.46 & 1.44 \\
\hline & & & & & &
\end{tabular}




\begin{tabular}{ccccccc}
$\begin{array}{c}\text { Nomor } \\
\text { Indikator }\end{array}$ & $X i$ & $Y i$ & $T k i$ & $X$ & $Y$ & Gap \\
\hline 23 & 284 & 451 & $63 \%$ & 2.87 & 4.56 & 1.69 \\
\hline 24 & 282 & 445 & $63 \%$ & 2.85 & 4.49 & 1.65 \\
\hline 25 & 293 & 437 & $67 \%$ & 2.96 & 4.41 & 1.45 \\
\hline 26 & 303 & 455 & $67 \%$ & 3.06 & 4.60 & 1.54 \\
\hline
\end{tabular}

Indikator yang terdapat pada kuadran III ini adalah indikator yang dianggap kurang penting bagi responden dan kinerja yang dilakukan pengelola juga kurang diperhatikan karena indikator pada kuadran ini merupakan indikator yang kurang berpengaruh pada

\section{Analisis Kesenjangan (Gap) antara Kinerja dan} Harapan

Penghitungan kesenjangan (gap) antara kinerja dan harapan dilakukan dengan mengurangi nilai rata-rata harapan (Y) dengan nilai rata-rata kinerja (X). Berdasarkan Tabel 3 terlihat bahwa kawasan merokok, ruang baca dan hotspot area memiliki nilai kesenjangan terbesar $(1,80)$, selanjutnya diikuti dengan jaminan keselamatan $(1,69)$ dan keamanan serta kenyamanan di terminal $(1,65)$.

\section{Analisis Kuadran}

Pengukuran Importance-Performance Analysis pada 26 indikator dijabarkan ke dalam diagram Kartesius yang dibatasi oleh sumbu $X$ dengan nilai rata-rata kinerja dan sumbu $Y$ dengan nilai rata-rata harapan.

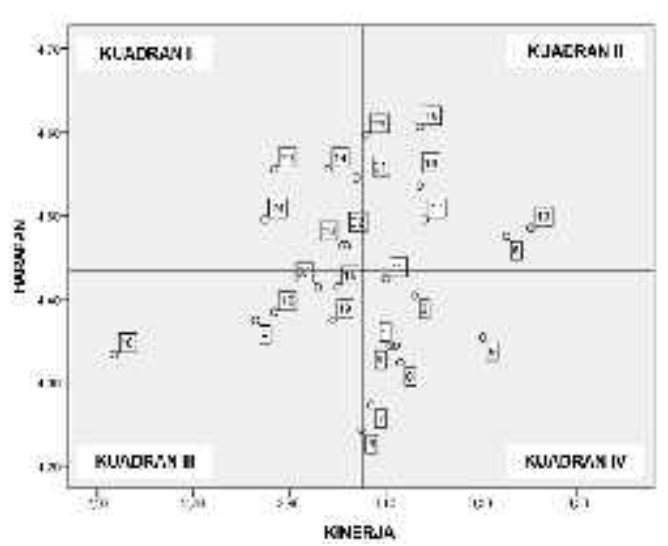

Gambar 2. Diagram Kartesius IPA

Kuadran I menunjukkan bahwa indikator harus lebih diperbaiki agar kinerjanya meningkat dan menjadi lebih baik lagi karena indikator ini mempunyai nilai harapan yang tinggi tetapi nilai kinerja masih kurang memuaskan. Indikator pada kuadran I ini meliputi: ketersediaan fasilitas untuk pengguna disabilitas (indikator 14), penyampaian informasi gangguan perjalanan bus dengan jelas (indikator 20), informasi keberangkatan dan kedatangan bus selalu tersedia (indikator 21), informasi pelayanan terletak di tempat strategis (indikator 22), Pengguna terminal mendapatkan jaminan keselamatan (indikator 23), pengguna merasa aman dan nyaman di terminal (indikator 24).

Selanjutnya kuadran II menunjukkan bahwa nilai harapan tinggi dan nilai kinerja dianggap sudah sangat penting sehingga responden merasa puas. Indikator pada kuadran II antara lain: adanya petugas keamanan di Terminal (indikator 5), terdapat tempat parkir kendaraan umum dan pribadi yang cukup (indikator 13), Jadwal keberangkatan dan kedatangan kendaraan tepat (indikator 16,. loket penjualan tiket tetap dan teratur (indikator 17), letak jalur keberangkatan dan kedatangan kendaraan tetap dan teratur (indikator 18), seluruh petugas di terminal selalu tersedia dalam melayani (indikator 26). kepuasan responden. Indikator pada kuadran III antara lain: jumlah pos, fasilitas dan petugas kesehatan yang cukup (indikator 3), jumlah pos keamanan, kamera pengawas/CCTV dan titik pengamanan yang cukup (indikator 4), kawasan merokok, ruang baca dan hotspot area yang cukup (indikator 10), tempat penitipan barang dan fasilitas pengisian baterai (charging area) yang cukup (indikator 12), ruang tertutup khusus beserta fasilitas lengkap untuk ibu menyusui dan bayi yang memadai dan bersih (indikator 15), informasi fasilitas keselamatan dan kesehatan tersedia dengan jelas (indikator 19), dan adanya media pengaduan gangguan keamanan (indikator 25).

Kuadran ini menunjukkan bahwa indikator yang dirasakan kurang penting bagi responden tetapi kinerja yang dilakukan pengelola sudah dengan baik sehingga responden merasa puas. Indikator pada kuadran IV antara lain: adanya lajur pejalan kaki yang aman (indikator 1), fasilitas keselamatan yang memadai (jalur evakuasi dan alat pemadam kebakaran) (indikator 2), tempat duduk dengan kapasitas memadai (indikator 6), toilet dengan jumlah yang cukup (indikator 7), fasilitas ibadah memiliki luas yang cukup (indikator 8), dan adanya petugas kebersihan di Terminal (indikator 9).

\section{KESIMPULAN}

Seiring dengan beroperasinya jalan tol Trans Jawa, akan lebih menarik masyarakat untuk menggunakan moda berbasis jalan termasuk bus. Terminal Kampung Rambutan sebagai salah satu terminal Tipe-A di Jakarta akan menjadi salah satu titik transit penumpang dan bus yang bepergian ke kota-kota di pulau Jawa. Sehingga kualitas pelayanan terminal menjadi sangat penting dalam menjamin perpindahan penumpang dan barang yang lancer, aman, dan nyaman. Kinerja pelayanan yang prima dengan tersedianya berbagai fasilitas yang disyaratkan dan juga pengelolaan yang baik akan meningkatkan tingkat kepuasan penumpang bus/pengguna terminal.

Berdasarkan hasil analisis disimpulkan bahwa pengguna terminal merasa kurang puas terlebih untuk beberapa indikator pelayanan seperti penyediaan fasilitas untuk difabel, penyampaian informasi gangguan perjalanan kendaraan bus, ketersediaan informasi keberangkatan dan kedatangan kendaraan, lokasi Informasi pelayanan yang strategis (mudah didengar dan jelas terbaca), serta keamanan dan kenyamanan di terminal. Sehingga perbaikan ke depannya juga dapat mempertimbangkan hasil temuan ini. Ke depannya penelitian serupa tidak hanya mengevaluasi kualitas pelayanan dari sisi pengguna saja, tetapi juga berdasarkan Standar Pelayanan Minimal yang disyaratkan pemerintah. 


\section{REFERENS}

Idris, Z., (2009). Kajian Tingkat Kepuasan Pengguna Angkutan Umum di DIY. 9 (2): 191.

Irawan, H., (2004) Kepuasan Pelayanan Jasa. Jakarta: Erlangga.

Keputusan Menteri Perhubungan Nomor 31 Tahun 1995 Tentang Terminal transportasi jalan.

Parasuraman, A., dkk. (1990), Delivering Quality Service Balancing Customer Perceptions and Expectation. New York: The Free Press.

Peraturan Menteri Perhubungan Republik Indonesia Nomor 40 Tahun 2015 Tentang Standar Pelayanan Penyelenggaraan Terminal Penumpang Angkutan Jalan.

Peraturan Menteri Perhubungan Republik Indonesia Nomor 132 Tahun 2015 Tentang Penyelenggaraan Terminal Penumpang Angkutan Jalan.

Rangkuti, F., (2003), Measuring Customer Satisfaction. PT. Gramedia Pustaka Utama Jakarta.

Sugiyono, (2013), Metodologi Penelitian Kuantitatif, kualitatif dan R \& D. Bandung: Alfabeta.

Swastha, B., (2000), Pengantar Bisnis Modern, Pengantar Ekonomi Perusahaan Modern, Jakarta: Liberty.

Undang-undang republik Indonesia Nomor 14 tahun 1992 Tentang Lalu lintas dan angkutan jalan.

Wibowo, A., S., (2013). Pengaruh Harga, Kualitas Pelayanan dan Nilai Pelanggan Terhadap Kepuasan Konsumen pada Rumah Makan di Kota Purwokerto. Semarang: Universitas Negeri Semarang.

Wright, P., H., Ashford, N., J., Stammer, R., J., (1997), Transportation Engineering Planning and Design, $4^{\text {th }}$ Edition, John Wiley \& Sons Inc 